\title{
DOS COLETIVOS POPULARES DE CAMPO GRANDE, RJ, AO MOVIMENTO ANTICAPITALISTA GLOBAL
}

\author{
Edivan Fulgencio ${ }^{1}$ \\ Orcid: https://orcid.org/0000-0001-6747-8541
}

Recebido em: 21 mar. 2021

Publicado em: 28 abr. 2021

\section{RESUMO}

No contexto mundial de desafios globais, muito se tem repetido a dicotomia "Pensar global, Agir local". As ações e mobilizações coletivas em diferentes territórios e com variadas escalas espaçotemporais de organização e luta, parecem se adequar a esta lógica. No entanto para atingir a utopia possível do fim do modelo de acumulação capitalista, causa das crises e ameaça à paz e segurança mundial, bem como à própria continuidade da espécie humana e do meio natural, é necessário que as mobilizações sejam de ordem planetária. Embora à primeira vista se apresente como utopia, o surgimento de um novo modelo de organização social e econômica, de maior amizade entre os povos, mais equidade e justiça, a crise que o modelo atual de acumulação capitalista atravessa, indica ser possível substituí-lo, até por uma questão de sobrevivência. O presente artigo discute a possibilidade de iniciativas locais e identitárias como os coletivos populares de Campo grande, Rio de Janeiro, apresentarem potência para integrar as diferentes redes de indignação anticapitalista que eclodem ao redor do mundo e assim participar da construção do movimento anticapitalista global.

PALAVRAS-CHAVE: Utopia. Coletivos. Movimento anticapitalista global. Redes de indignação. Escala.

\section{FROM THE POPULAR COLLECTIVES OF CAMPO GRANDE, RJ TO THE GLOBAL ANTI-CAPITALIST MOVEMENT}

\begin{abstract}
In the global context of global challenges, the dichotomy "Think global, Act local" has been repeated a lot. Collective actions and mobilizations in different territories and with varying spatiotemporal scales of organization and struggle seem to fit this logic. However, in order to achieve the possible utopia of the end of the model of capitalist accumulation, which causes crises and threatens world peace and security, as well as the very continuity of the human species and the natural environment, it is necessary that the mobilizations be of a planetary order. Although at first glance it appears as a utopia, the emergence of a new model of social and economic organization, of greater friendship between peoples, more equity and justice, the crisis that the current model of capitalist accumulation is going through, indicates that it is possible to replace it, even for the sake of survival. This article discusses the possibility of local and identity initiatives such as the popular collectives of Campo Grande, Rio de Janeiro, presenting the power to integrate the different networks of anti-capitalist indignation that erupt around the world and thus participate in the construction of the global anti-capitalist movement.
\end{abstract}

\footnotetext{
${ }^{1}$ Professor de Geografia. Doutorando e Mestre em Geografia pela Universidade do Estado do Rio de Janeiro (UERJ). Especialista em Análise, Projeto e Gerência de Sistemas pela UNESA.
} 
KEYWORDS: Utopia. Collectives. Global anti-capitalist movement. Networks of indignation. Scale.

\section{INTRODUÇÃO}

Pensar globalmente, agir localmente. Expressão atribuída ao sociólogo alemão Ulrich Beck, especialista no tema Globalização, muito utilizada recentemente, inclusive por líderes mundiais como o Papa Francisco (2015) em sua defesa de uma nova economia com mais justiça, inclusão social e preservação do meio ambiente, iniciando-se em práticas singelas das comunidades até ganhar peso de decisões estratégicas globais. Seu uso, torna-se muito apropriado para estes tempos de desafios em escalas espaçotemporais que vão de dias difíceis em comunidades a décadas de recessão e crise do sistema mundo.

Nos apropriamos desta expressão neste artigo para defender a ideia da possibilidade de pensar a utopia do surgimento de um movimento anticapitalista planetário, capitaneado a partir de práticas locais, cuja escala possa evoluir para acionamentos de sentimentos de pertencimento e engajamento globais.

Passada meia década do golpe institucional impetrado contra o governo democraticamente eleito de Dilma Roussef, pelas elites brasileiras do atraso, insatisfeitas com as importantes mudanças na economia brasileira a partir do início do século XXI, é flagrante a derrocada dos direitos básicos conquistados pelas classes trabalhadoras e mesmo excluídas. O meio ambiente é tratado como mercadoria sem valor, a qual pode ser consumida sem pudor ou destruída na troca por outras consideradas mais valiosas (o espaço florestal, por campo para produção e exploração de comodities, por exemplo).

Em paralelo, a crise de representatividade da cidadania popular se manifesta no avanço de grupos da extrema-direita, financiados por empresários e grupos políticos inescrupulosos. Os governos de cunho social que aproveitaram o bom momento de forte crescimento das chamadas "economias emergentes", como o Brasil e através de estratégias desenvolvimentistas, promoveram o crescimento de regiões menos favorecidas em cenários anteriores, foram substituídos por figuras populistas, cunhadas a partir do fenômeno do neopentecostalismo religioso e das fake news capitaneadas pelas classes hegemônicas. Estes fatos, observados de forma dramática sobretudo pela consequência na vida dos mais pobres e nas ameaças às minorias, vão se dar no Brasil e se repetir em diferentes escalas em países da América do Sul, como Chile, Bolívia, Peru. Bem como, em regiões menos favorecidas pelo capital no mundo globalizado. 
Em contraponto, eclodem nas últimas décadas importantes movimentos, os quais reconfiguraram territórios e as formas tradicionais de organização política, motivando e mobilizando o povo para a luta, os coletivos populares. Estas mobilizações, na maior parte das vezes extremamente informais e com estruturas heterodoxas e inovadoras têm incomodado capitalistas ao redor do mundo, através de impactantes movimentos de contestação ao neoliberalismo, como os occupies, as primaveras dos povos, os levantes indígenas, entre outros. Articulam-se a partir destas mobilizações coletivas, redes mundiais para organização de diferentes movimentos contestatórios.

Podemos estar assistindo à gestação de um movimento anticapitalista global. Este artigo discute a possibilidade de coletivos como estes, porém atuantes numa escala geográfica menor, a Região Administrativa de Campo Grande (RA Campo Grande), na Zona Oeste do Rio de Janeiro, associarem-se a estas Redes de Indignação mundial, numa evolução da escala de mobilização, do local ao global. Participando assim da construção desta utopia de derrocada do capitalismo e do surgimento de uma nova forma de organização social pautada no bem comum, na paz e na amizade entre pessoas e entre diferentes povos.

\section{TORNAR A UTOPIA POSSÍVEL}

Quando o dia da paz renascer / Quando o Sol da esperança brilhar Eu vou cantar

Quando o povo nas ruas sorrir /E a roseira de novo florir

Eu vou cantar

Vai ser tão bonito se ouvir a canção / Cantada de novo No olhar da gente a certeza de irmãos / Reinado do povo. Zé Vicente ${ }^{2}$

Em “Utopia”, canção do poeta, lavrador e cantador cearense, Zé Vicente, a realização da utopia é uma esperança carregada de certeza, expressa pelo adverbio que define um tempo, 'QUANDO', ao invés do uso de uma situação hipotética, caso fosse utilizado uma condicional 'se'. Intercalado com a futurística, porém afirmativa locução verbal "VAI SER". É sobre a possibilidade da concretização da utopia de um mundo melhor, com uma organização de mundo diferente da vigente neste momento histórico, que pretendemos refletir aqui, trazendo novas formulações políticas as quais podem efetivar um reinado efetivamente do povo.

\footnotetext{
${ }^{2}$ VICENTE, Zé. Utopia. In: Festa dos pequenos. Paulinas - Comep, 989, LP. Disponível em Portal MPBNet, Zé Vicente (mpbnet.com.br), acesso em 20.mar.2021.
} 
Estamos assistindo neste início de século, a degradação social, ambiental e das relações humanas, demonstrando indícios do desmoronamento da sociedade de consumo capitalista como projeto de organização social.

Atualmente, o enfrentamento mundial à onda neoliberal, com resistências em diversos países às modificações nas aposentadorias, com a defesa da educação e saúde públicas gratuitas e de qualidade, as lutas pelos direitos humanos, a defesa do meio ambiente e de minorias, entre outras e inúmeras pautas, vêm animando grupos a se mobilizarem coletivamente ao redor do mundo.

Uma vez que estas iniciativas evoluam para estruturas interseccionais e interescalares, evoluindo na escala espacial de lutas locais, saltando para regionais e possivelmente inclusive pautas globais. Valendo-se entre outras ferramentas de organização, das modernas Tecnologias da Informação e Comunicação (TIC), entendemos que, os coletivos urbanos, uma vez organizados e bem estruturados podem atender à esperança de Harvey (2016, p. 246) de que a partir das inciativas coletivas locais "surjam movimentos sociais e políticos que digam "Já basta!" e mudem nosso modo de viver e amar, sobreviver e nos reproduzir". Tendo potência assim, para impactar o ciclo atual do modelo de acumulação capitalista.

A sociedade atual, antecipadamente entendida por Harvey (1989) como uma compressão espaço-tempo, parece extrapolar a tríade geo-histórica de Santos (2006) meionatural, meio-técnico, meio-técnico-científico-informacional. Vai ser percebida por Leopoldo (2016), como uma sociedade neoliberal, globalizada e sua característica de organização em rede, propiciada pelo enorme avanço tecnológico das telecomunicações e meios de transporte. Esta nova estruturação espacial global e, ao mesmo tempo, regional vai configurar a sociedade metropolitano-financeira, como modelo substituto do modelo urbano-industrial.

A economia metropolitano-financeira é uma nova fronteira capitalista, um novo momento articulado e convergente à economia agrário-comercial e economia urbanoindustrial. Ela domina, mas mantém traços, processos e contradições vinculadas às economias precedentes. Cada uma dessas economias determina meios para suas respectivas sociedades e mobiliza espaços e tempos de seu presente histórico e geográfico (LEOPOLDO, 2016, p.9).

Porém, esta nova organização social e econômica, como fruto de mais uma evolução do processo histórico capitalista, se revela como mais um aprofundamento da crise que afasta as pessoas espacialmente, ao mesmo tempo, em que as segrega socialmente.

Para a classe operária, rejeitada dos centros para as periferias, despojada da cidade, expropriada assim dos melhores resultados de sua atividade, esse direito tem um alcance e uma significação particulares. Representa para ela ao mesmo tempo um meio e um objetivo, um caminho e um horizonte; mas essa ação virtual da classe 
operária representa também os interesses gerais da civilização e os interesses particulares de todas as camadas sociais de "habitantes", para os quais a integração e a participação se tornam obsessivas sem que cheguem a tomar eficazes essas obsessões [...] Só o proletariado pode investir sua atividade social e política na realização da sociedade urbana. Só ele também pode renovar o sentido da atividade produtora e criadora ao destruir a ideologia do consumo. Ele tem portanto a capacidade de produzir um novo humanismo, diferente do velho humanismo liberal que está terminando sua existência: o humanismo do homem urbano para o qual e pelo qual a cidade e sua própria vida cotidiana na cidade se tomam obra, apropriação, valor de uso (e não valor de troca) servindo-se de todos os meios da ciência, da arte, da técnica, do domínio sobre a natureza material. (LEFEBVRE, 2008. p.139, 140).

Busca-se, então, organizar a resistência ao sistema capitalista e sua apropriação do espaço. Bem como, propor e construir uma nova forma de vida, em um novo meio social transformado e renovado por novas e mais humanas relações sociais.

Nossa utopia, apreendida no contato com os coletivos populares, espaços de luta pelo direito à cidade, contrapondo-se ao cenário de unificação global do pensamento e do modo de vida afetado pelas contradições próprias da sociedade capitalista neoliberal, é de que estas mobilizações locais sejam os agentes mobilizadores e motivadores da estruturação e organização de contestações sociais, com a potência da identidade de cada um, porém reconfiguradas na possibilidade de mobilização e execução da mudança a partir das ações de muitos. Ou seja, a coletividade, de onde pode surgir um movimento anticapitalista global, estruturado e único, conforme Harvey (2016)

\footnotetext{
Imagine ainda, se a alienação da experiência contemporânea do trabalho, do consumo compensatório que nunca satisfaz, dos níveis incalculáveis de desigualdade econômica e discordância na relação com a natureza diminuísse por conta de uma onda de descontentamento popular com os excessos do capital. [...] os movimentos de oposição - altamente fragmentados, mas numerosos - podem convergir e se juntar num movimento solidário mais unificado contra o domínio do capital. (HARVEY, 2016, p.247).
}

Para nós, esta utopia é uma construção possível. Desde que, os coletivos e mobilizações em andamento, construídas e articuladas sob as mais diversas pautas: direitos humanos, questões étnico-raciais, direito das mulheres, LGBTQIA+, indígenas, justiça socioambiental e tantas outras, possam se organizar em um único movimento revolucionário planetário, conforme proposto por Harvey (2016). Haja vista, a ocorrência de mudanças importantes na economia mundial a partir do início do século XXI, tornadas possíveis por governos de origem popular formados a partir de partidos oriundos dos movimentos sociais. Estes governos com soluções por vezes originais e simples, aproveitaram o bom momento de instabilidade e crises das potências mundiais para levar avante processos de aproximação que alavancaram forte crescimento das chamadas "economias emergentes". 
O Brasil se tornava uma das economias que mais cresciam no mundo. Vai apresentarse como líder de importantes iniciativas junto a seus pares, como a formação do BRICS e o Mercosul, a inclusão dos emergentes nas mesas de negociação mundial com criação do G20, proposição e liderança soberana em diversos acordos multilaterais. Além de costuras políticas e econômicas do Sul planetário, as quais vão ter como consequência uma maior inserção da África e América Latina no cenário decisório mundial e no contexto interno, uma maior inclusão social, com impactos como a diminuição do flagelo da fome, miséria e a inserção de classes populares no mercado de consumo.

Porém, o "partido de Wall Street", expressão de David Harvey (2014) para representar os $1 \%$ de ricos que controlam a economia mundial, contra os $99 \%$ que vivem apenas com o mínimo suficiente, ou nem sequer isso. Ao redor do mundo, assim, como na questão posta pelo Movimento Occupy Wall Street, não aceitam perder ou abrir mão de seus lucros exorbitantes, ainda que em vista do bem-estar social de muitos outros.

O contra-ataque capitalista, com aceleração da agenda neoliberal, o ataque às instituições e às agendas multilaterais, rompimento de acordos como o climático e o antinuclear, ascensão e chegada ao poder da extrema-direita ao redor do mundo são desafios postos às camadas populares ao redor do mundo, sobretudo durante a década de 2010.

\begin{abstract}
A luta que se criou - o Povo contra o Partido de Wall Street - é crucial para nosso futuro coletivo. A luta é global assim como local em sua natureza. Reúne estudantes confinados a uma luta de vida ou morte contra o poder político no Chile para criar um sistema de educação gratuito e de qualidade para todos, desmantelando o modelo neoliberal que Pinochet impôs brutalmente. Engloba os ativistas da praça Tahrir que reconhecem que a queda de Mubarak (como o fim da ditadura de Pinochet) foi apenas o primeiro passo de uma luta para emancipar-se do poder do dinheiro. Inclui os indignados da Espanha, os trabalhadores em greve na Grécia, a oposição militante que surge em todo o mundo, de Londres a Durban, Buenos Aires, Shenzhen e Mumbai. A dominação brutal do grande capital e o poder do dinheiro estão na defensiva em todo lugar. De que lado vamos estar, nós, indivíduos? Que rua vamos ocupar? Só o tempo dirá. Mas o que sabemos é que o tempo é agora. O sistema não está só quebrado e exposto, mas também incapaz de qualquer resposta a não ser a repressão. Então nós, o povo, não temos outra opção senão lutar pelo direito coletivo a decidir como o sistema será reconstruído e com base em qual modelo. O Partido de Wall Street teve sua vez e fracassou miseravelmente. Como construir uma alternativa em suas ruínas é tanto uma oportunidade inescapável quanto uma obrigação que nenhum de nós pode ou vai querer deixar de lado. (HARVEY, 2012). ${ }^{3}$
\end{abstract}

A construção de alternativas e respostas vem sendo dada por diferentes povos ao redor do mundo, como povos do Chile, Bolívia e Venezuela, na América Latina, através da

\footnotetext{
${ }^{3}$ HARVEY, David. Os rebeldes na rua: o Partido de Wall Street encontra um adversário. Blog da Boitempo. Publicado em 02/04/2012. Disponível em: https://blogdaboitempo.com.br/2012/04/02/os-rebeldes-na-rua-opartido-de-wall-street-encontra-um-adversario-artigo-de-david-harvey/. Acesso em: 09.nov.2020.
} 
participação popular em iniciativas como o Fórum Social Mundial, a Assembleia mundial dos povos (Inclusive indígenas) e Organizações de agendas de mobilização comuns: A Internacional Progressista; a Aliança dos Povos e a Habitat International Coalition (HIC), para citar alguns exemplos.

Estes grupos que vão se constituindo ao redor do mundo, com a facilidade de interconexão das redes e a velocidade dos modernos meios de transporte, extrapolando espaço e tempo vêm criando oportunidades de oposição forte e estruturada às contradições causadas pelos processos de produção capitalista do espaço e seus agentes. A partir desta realidade, entendemos ser possível o desenvolvimento dos coletivos populares como alternativa de resistência e mobilização popular, entre os quais se situam os coletivos da Zona Oeste do Rio de Janeiro, desde que interconectando-se em rede às Mobilizações anticapitalistas globais. Assumindo um lugar e papel de relevância e destaque, através de seus diferentes modos de atuação nos diferentes contextos políticos territoriais, evoluindo para escalas e pautas de lutas anticapitalistas globais.

Em Campo Grande, ao menos dez iniciativas de mobilizações coletivas se apresentam para a luta e resistência anticapitalista, com potencial para integrar esta eventual mobilização mundial:

- Coletivo de Educação Popular Margarida Maria Alves

- Coletivo Negro Waldir Onofre

- Coletiva Popular de Mulheres da Zona Oeste

- Rede Carioca de Agroecologia Urbana (Rede CAU) - Rio da Prata

- IFHEP - Instituto de Formação Humana e Educação Popular

- Coletivo (R)existe Campo Grande

- MIR ZO - Movimento Inter-religioso da Zona Oeste

- Coletivo Cultura ZO

- Coletivo Cultural do Rio da Prata

- Coletivo Tudo numa coisa só.

Entre outros grupos e iniciativas insurgentes com potencial capaz de agregar coletivamente diferentes demandas não atendidas pelo capitalismo representado pelo estado subserviente e cooptado, podendo integrar em rede o movimento revolucionário global pensado por Harvey (2016).

O espaço urbano é o lócus onde se dá a luta política, entre capitalistas cooptando o Estado e os cidadãos (re)presentados (pelos) nos movimentos sociais, entre os quais, se situam os coletivos urbanos. Estes agentes disputam entre si de forma conflituosa. Na resolução destes 
conflitos se dá a política urbana, a qual reconfigura continuamente o espaço urbano. As formas como se dão os conflitos e como o poder público apresenta ou negligencia soluções vai impactar nas ações e reações dos coletivos e movimentos sociais. Esta dinâmica da política urbana pretendemos apresentar de forma esquemática abaixo, a qual foi construída a partir da experiência junto aos coletivos de Campo Grande, RJ e como uma analogia ao esquema de Política Urbana proposto por Castells (1983). Entendemos que o esquema atende à dinâmica local x global da representatividade dos cidadãos e classe trabalhadora pelos diferentes coletivos e suas manifestações frente aos centros de poder e decisão locais ou globais.

Figura 1 - Esquema da disputa pelos comuns urbanos no contexto dos coletivos populares

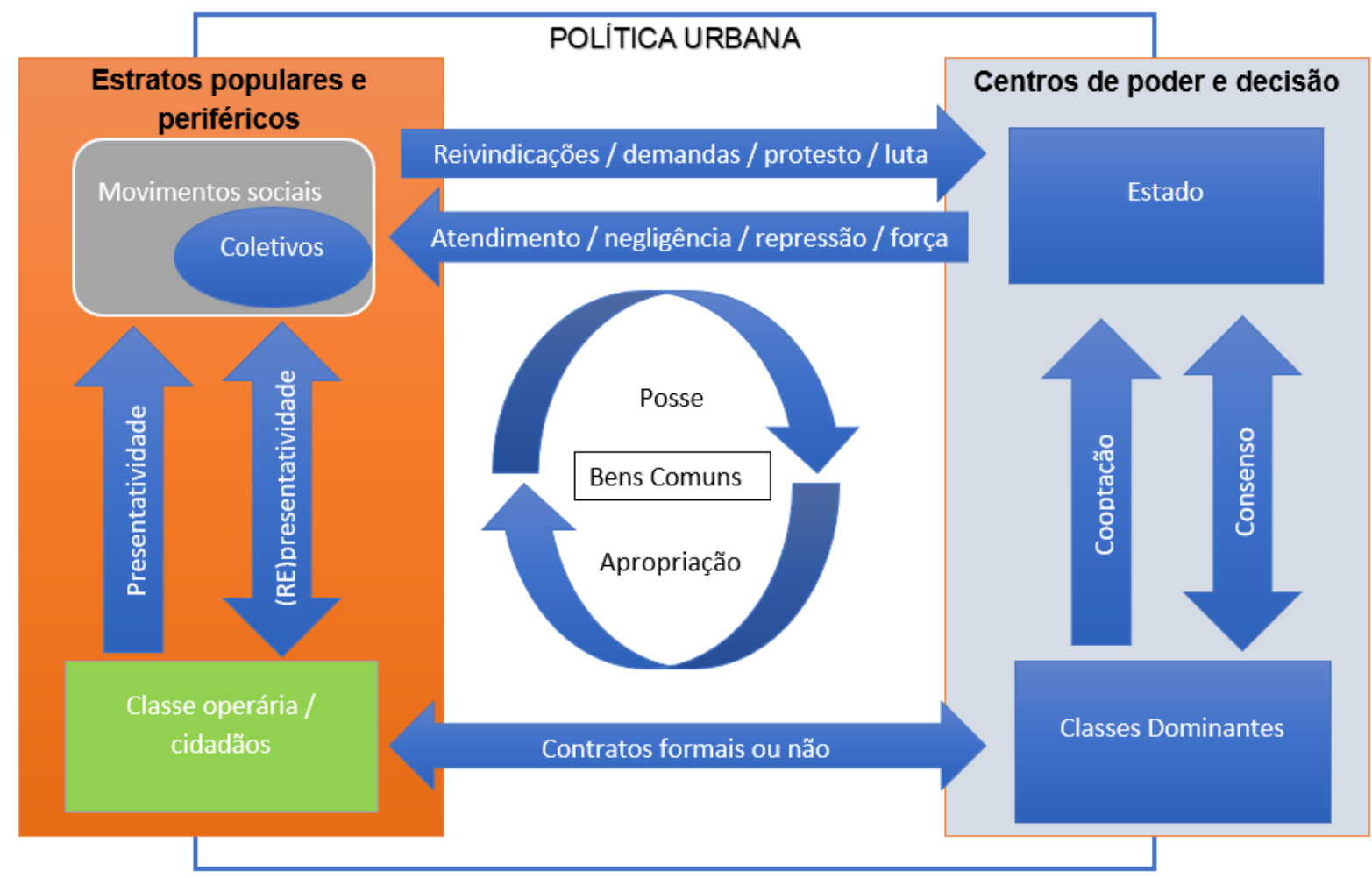

Fonte: elaborado pelo autor, 2020.

A partir do esquema proposto, entendemos a política urbana, como uma disputa efetivada através de demandas e reivindicações dos cidadãos e seu atendimento ou negligência por parte do Estado. Harvey (2014) enxerga estas demandas por bens e serviços como uma disputa pela posse ou apropriação dos comuns urbanos

Os cidadãos, em sua maioria pertencentes às classes trabalhadoras ou excluídas, ou seja, os estratos populares, estabelecem contratos (formais ou não) com as classes dominantes. $\mathrm{O}$ 
Estado neoliberal, preponderante na ordem mundial atual, cooptado pelas classes dominantes, as favorece em suas decisões, estabelecendo uma relação injusta de consenso com os capitalistas.

Diante deste cenário de disputa injusta pelos bens comuns, os cidadãos vão reclamar demandas diversas. Uma vez não atendidas, as demandas vão se tornar bandeiras de lutas das mais diferentes identidades e pautas. Os coletivos urbanos representam uma forma diferenciada, até mesmo diante dos movimentos sociais tradicionais, de organização para a disputa pela apropriação ou posse dos bens comuns, que deveriam lhe ser garantidos por direito.

Esta disputa colocada na escala local, a partir do ponto de vista do urbano que é a maior representação do espaço mundial, pode ser escalonada para pautas globais. A forma de apropriação injusta e desigual dos bens e serviços pelas classes dominantes, vai influenciar diretamente as pautas identitárias: negros, mulheres, indígenas, trabalhadores urbanos e rurais, sem-teto, etc. Haja vista a histórica concentração de renda e posses nas mãos de homens brancos, fazendeiros, comerciantes ou industriais.

Configura-se assim, a disputa de classes, como a base de diferenças sociais históricas, as quais vão se manifestar no mundo globalizado em preconceitos, machismo, racismo, xenofobia, lgbtfobia, e toda gama de injustiças sociais, com impactos desumanizantes nas classes menos favorecidas, além de, a partir da década de 1970 configurar-se também na degradação ambiental e no aquecimento global, a níveis de ameaça à própria continuidade da vida no planeta. Como consequências, observa-se o agravamento dos desastres naturais, bem como os incidentes ecológicos de origem antrópica e o surgimento de novas e mais desafiadoras doenças, como a atual pandemia da COVID-19. Consequências estas muito maiores e perversas com as classes menos favorecidas, sobretudo nas periferias mundiais.

Entendemos esta segregação socioespacial, causada pela gestão desigual de investimentos como uma não-política de Estado. Esta não política ao impactar na qualidade e mesmo na expectativa de vida do povo, produz revolta traduzida em cobrança das demandas através de reivindicações. As quais muitas vezes, extrapolam para conflitos violentos como depredações do patrimônio público, ataques violentos às autoridades, os quais muito embora, na maior das vezes justamente, vão trazer prejuízos aos serviços e perdas materiais (inclusive de vidas) aos próprios estratos populares. Neste contexto, o surgimento dos diferentes coletivos populares, apresentam-se como forma de organização para as mobilizações de protesto e luta.

Como resultado das reivindicações e mobilizações coletivas podemos ter alguma de diferentes situações: 
i. O atendimento das pautas, como uma forma de concessão do Estado. Nestes casos, pode inclusive se levar a um relaxamento e acomodação das lutas pelas causas maiores; ou

ii. A negação pelo Estado, com possíveis radicalizações e prováveis tentativas de apropriação e posse dos bens ou serviços disputados, com a consequente repressão do Estado. Muitas vezes com uso de força repressiva excessiva

No território analisado, o uso desproporcional da força pelo aparato oficial - ou, muitas vezes, conforme Cano e Duarte (2012), se valendo de grupos de poder paralelo, funciona da forma mais cruel, na forma da lei do mais forte. É comum os moradores ainda que com razão para reivindicar bens e direitos como saúde, saneamento, educação, por mera questão de sobrevivência aparentam se calar diante das injustiças ou repetir as formas populares "manda quem pode, obedece quem tem juízo"; "não mexe com isso, não!”. Além de muitas vezes se voltarem contra os próprios ativistas e agentes dos movimentos sociais e coletivos. Impedidos assim de atuar em seus territórios, por melhorias para suas próprias comunidades.

Estas experiências coletivas locais, carregam então um potencial, uma energia tal que uma vez organizadas e atingindo escalas globais, podem somar forças para se tornarem o indício da derrocada do modelo de acumulação capitalista atual. O sistema capitalista cada vez mais apresenta sua incapacidade em atender à totalidade das demandas humanas de forma igualitária. Um exemplo é o drama da produção e distribuição das vacinas contra o Corona Vírus. Esta impotência do Sistema hegemônico pode funcionar como um motor de indução da insatisfação popular contra as mazelas causadas pela extrema desigualdade, contraditórias com a natureza humana, as quais estão expondo as pessoas não mais apenas ao desemprego, às condições insalubres de residência, à falta de água potável e comida. Cada vez mais a ameaça é à vida das pessoas.

Esta insatisfação popular, corretamente canalizada e organizada por grupos liderados por nomes respeitados das ciências, das artes e mesmo da espiritualidade, os quais já começam a se formar e se organizar, como o Fórum Social Mundial, a [Frente] Internacional Progressista, Marcha Mundial das Mulheres, a Aliança Mundial dos Povos Indígenas, entre outros. Além das diversas redes de coletivos que vão se organizando a partir de diferentes regiões do planeta. Das periferias brasileiras, como a Rede Favela Sustentável, a organizações de revolucionários nigerianos, como o CORE (Coalition for Revolution), se organizando sobretudo através das redes de informação e comunicação facilitadas pelo uso, embora ainda excludente, porém cada 
vez mais massivo da Internet, no que Castells (2017) vai chamar de Redes de Indignação e Esperança.

Esta onda que vai ganhando corpo ao redor do mundo, infelizmente no Brasil muito retardada sobretudo pela influência do conservadorismo cristão manipulado pela mídia, partidos de direita e pela elite conservadora, pode se transformar em rebeldia coletiva contra o sistema, tendendo a crescer a um estado de revolta, a ponto de formar movimentos de insurgência e, estes sim, acabarem por desfigurar o capitalismo, ao menos como ele é conhecido neste momento histórico.

Harvey (2016) vai chamar este risco de desestruturação do sistema capitalista, de contradições perigosas do capitalismo. Uma possível revolta popular global, seria surpreendente para as classes dominantes, haja vista a acomodação das mesmas frente a uma aparentemente eterna alienação coletiva. A revolta típica da natureza humana frente a esta alienação é uma das contradições fatais, as quais podem levar o sistema de acumulação capitalista ao colapso derradeiro, ao menos da forma em que se apresenta hoje.

Destes grupos surgidos a partir da década de 2010, sobretudo como resposta à retomada ultraliberal mundial com a eleição de Donald Trump e outros tantos clones ao redor do mundo, como o fatídico capitão do mato brasileiro, entendemos a Internacional Progressista como o mais proeminente e capacitado a obter ou gerar resultados concretos, como o questionamento da imposição das políticas neoliberais pela União Europeia aos países membros, assim como a submissão com consequente guinada ultraliberal dos países latino-americanos ao imperialismo norte-americano.

Frente formada a partir de um encontro de intelectuais e líderes progressistas e mundiais convocado por Sanders em setembro de 2018, a partir da União do Instituto Sanders ${ }^{4}$ ao Movimento DiEM25도 a Internacional Progressista busca através de, em suas palavras, uma visão compartilhada do mundo: mobilizar, unir e organizar as forças progressistas mundiais.

\footnotetext{
Declaração

I. Internacionalismo ou extinção. As crises de nosso século ameaçam a extinção de todas as formas de vida em todas as nações, em todos os continentes. O internacionalismo não é um luxo. É uma estratégia de sobrevivência. II. Uma definição de progresso. Nossa missão é construir uma frente planetária de forças progressivas. Definimos progressivo como a aspiração a um mundo que seja:
}

\footnotetext{
${ }^{4}$ Plataforma de discussão política e aglutinação de forças do senador democrata estadunidense Bernie Sanders.

${ }^{5}$ O Movimento Democracia na Europa 2025, ou DiEM25, é um movimento político pan-europeu lançado pelo exministro das Finanças grego, Yanis Varoufakis. Seu movimento visa reformar as instituições existentes da União Europeia para criar uma "democracia plena com um parlamento soberano respeitando a autodeterminação nacional e compartilhando o poder com parlamentos nacionais, assembleias regionais e conselhos municipais". Fonte: Open Democracy. https://www.opendemocracy.net/en/author/diem25/ , acesso em 21.mar.2021.
} 
democrático, descolonizado, justo, igualitário, libertado, feminista, ecológico, pacífico, pós-capitalista, próspero, plural e limitado pelo amor radical. III. Povos do Mundo, Organizem-se. Somos trabalhadores, camponeses e povos do mundo que se levantam contra as forças reacionárias da oligarquia autoritária. Nosso objetivo é uma organização internacional: combinar forças através das fronteiras para reivindicar o planeta como nosso. [...] (International Progressive, 2018) ${ }^{6}$.

Passados menos de 3 anos do lançamento da Internacional Progressista, ela hoje já desponta como uma frente capaz de aglutinar forças dos mais diferentes espectros políticos, seja partidos ou movimentos sociais, até organizações não governamentais, entidades de cunho religioso ou espiritual, o que faz todo o sentido, pois apesar da força estruturante de mobilização popular representada pelos diversos coletivos, a mudança no paradigma organizativo da sociedade mundial passa indubitavelmente pela política institucional. Segundo Carneiro (2011, p.12) "a construção de um movimento anticapitalista global não pode simplesmente abdicar de partidos, eleições e sindicatos, sob pena de esse espaço continuar a ser ocupado pelos partidos de direita".

Essa junção de forças institucionais progressistas aos diferente grupos identitários gerou a união de forças oriundas de diversos segmentos da sociedade, cada uma do seu jeito afetada pela forma espoliativa como o sistema capitalista as trata.

Partidos de trabalhadores e socialistas das Américas Latina, Caribe e Europa, grupos revolucionários da África e Ásia, organizações de mídia convencional ou alternativa de todo o mundo, sindicatos e centrais de trabalhadores formais ou informais como os entregadores e motoristas de aplicativo ao redor do mundo, entidades de luta pela paz e por direitos humanos, de mulheres, negros, lgbtqi e outras minorias ao redor do mundo. Representantes dos refugiados, dos sem-teto, movimentos de sem-terra, numa gama de dezenas de organizações ao redor de todo o mundo, contemplando todos os continentes e dezenas de países representados.

Ou seja pode sim ser possível tornar a utopia possível.

\section{MOBILIZAÇÕES COLETIVAS E O FIM DO CAPITALISMO}

Na RA Campo Grande, RJ, a luta que se efetiva caracteriza-se pela cisão e disputas entre grupos políticos dos mais diversos interesses, pelos escassos bens e serviços ofertados pelo poder público a uns poucos e negligenciados a muitos. Os coletivos populares e suas mobilizações em rede ou territoriais, se apresentam como foco de resistência local à apropriação

\footnotetext{
${ }^{6}$ Declaração Política da cúpula de lançamento da Internacional Progressista em setembro de 2018 (Tradução livre, do autor). Disponível em: https://cloud.progressive.international/s/F767W5iQ2GCN3ee\#pdfviewer , acesso em 21.mar.2021.
} 
capitalista do espaço. Agregam assim, potencial de se conectarem às diferentes redes de movimentos e partidos e participarem da construção dialeticamente utópica e possível de um movimento revolucionário anticapitalista mundial.

Fulgencio (2020) observa os coletivos populares atuando no território pesquisado, sob duas formas, as quais podem se manifestar de maneiras únicas ou conjugadas:

\begin{abstract}
i - da inserção e participação na política institucional e a partir daí ganhar escala de luta que vai do local até o global, através da militância independente, próxima e relacionada a movimentos, partidos e organizações institucionalizadas, disputando e concorrendo a cargos políticos e espaços de decisão nas diferentes esferas de poder. É o caso, por exemplo, do coletivo Tudo Numa Coisa Só, e mais recentemente, se apresentando efetivamente para a disputa das eleições municipais de 2020, a Coletiva Bem Viver.
\end{abstract}

ii - da aglutinação de forças populares, muitas vezes avessas ou descrentes da política institucional e mobilizadas por ativistas e grupos engajados na conscientização popular e na articulação de movimentos e políticas, próximas aos partidos e organizações, mas sem relação declarada de militância, porém acompanhando e, muitas vezes inclusive, mas não necessariamente, participando e influenciando agentes da política partidária tradicional. É o caso do Coletivo de Educação Popular Margarida Maria Alves, da Coletiva de Mulheres da Zona Oeste e do Coletivo (R)Existe Campo Grande, entre outros ativos na região pesquisada (FULGENCIO, 2020, p.108)

A forma como esta região administrativa da Cidade do Rio de Janeiro se configurou, revela diferentes agentes e processos temporais e espaciais, os quais transformaram um espaço predominantemente rural em um espaço marcadamente urbano, com as problemáticas demográficas e sociais inerentes a esta transformação do espaço geográfico. Esta dinâmica conflituosa, característica da produção capitalista do espaço (Harvey, 2005), favoreceu o surgimento da resistência pelos moradores e representantes das classes trabalhadoras.

A negligência do Estado em relação ao processo da efetivação deste espaço urbano, inicia-se na falta de planejamento e acompanhamento do processo de implosão-explosão da metrópole em direção ao Oeste. Reproduz as estratégias de "limpeza" e "branqueamento" das populações e do espaço urbano centrais e de áreas consideradas nobres na década de 1960, necessárias à propaganda do regime militar e seu "milagre econômico" gerador da nova classe média e burguesia brasileira, a 'cidade maravilhosa', conforme Abreu (1987). O ponto culminante espacial desta estratégia é a remoção de cortiços e favelas do centro e Zona Sul da cidade, transferindo a população pobre e preta para regiões afastadas da cidade, como o entorno da Avenida Brasil, gerando ou superpovoando bairros pobres e periféricos como Campo Grande e arredores.

Na década de 1980 em diante, seguindo os planos nacionais de desenvolvimento que apontam para as áreas do Sudeste, entre o centro da metrópole carioca e a metrópole paulista, 
como o principal motor da industrialização nacional. Tendo as duas vias, uma cortando a metrópole do Rio, a BR 101 (nomeada Avenida Brasil, em seu trajeto pela cidade do Rio de Janeiro) e a Rodovia Presidente Dutra, como pontos propícios à instalação de um parque industrial. Ficando assim, as regiões dos novos subúrbios e a Zona Oeste do Rio, subordinadas cultural, social e economicamente aos espaços considerados "nobres", ou vistos como centros de decisão na cidade.

Está configurada a segregação espacial em relação ao restante da cidade, segundo Maricato (2000), reproduzindo no novo espaço urbano as velhas formas de coronelismo, e patriarcado herdadas da sociedade brasileira colonial, tendo como fato simbólico a utilização das antigas fazendas da região, como loteamentos urbanos ou terrenos para implantação de indústrias e focos de comércio.

Esta apropriação do espaço realizada de forma violenta e sem planejamento das consequências sociais por parte da elite e até financiada pelo Estado, produz revolta no povo simples e trabalhador característico da região, desafiando as noções de pertencimento e de comunidade. Como consequência, surgem organizações locais, como as dos pequenos agricultores locais, organizados contra os posseiros e a forma como se estava reconfigurando este espaço.

A tomada de consciência da transformação espacial do rural em urbano carregada por uma forte segregação espacial, com consequências na qualidade de vida, na vida comunitária, na saúde e no meio ambiente, sem contrapartidas de serviços públicos e infraestrutura vai ganhando força ao longo das últimas décadas, produzindo sinergia em torno de causas comuns.

Proliferam em Campo Grande, as Associações de moradores, Associações de favelas, as Comunidades Eclesiais de Base e suas reuniões, assembleias, encontros, caminhadas, fechamento de ruas. Apropriação e posse de terrenos e toda sorte de ações similares às empreendidas pelos coletivos populares no século XXI. Haja vista muitos dos militantes e ativistas de agora, serem filhos e netos da classe rural, transformada em classe trabalhadora urbana. Sendo assim, testemunhas da dinâmica rural - urbano. A estes grupos vão se juntar jovens oriundos de remoções de favelas, ou trazidos para os novos conjuntos habitacionais, vindo de diferentes lugares da cidade, por vezes de forma arbitrária.

A maneira como o estado opera nesta dinâmica, ora como representante ora como parte da própria classe dominante e suas formas de produção do espaço urbano, expropriando comuns em espaços periféricos como a Região de Campo Grande, transferindo riqueza e renda dos mais pobres para os mais abastados, pode fazer aflorar nos cidadãos esta vocação para a reivindicação de direitos, marcante como característica histórica do povo esta região. 
Este impulso, entendido a partir de uma lógica coletiva, carregado de identidades particulares, expressas a partir das experiências, de cada um, conforme vimos anteriormente em escalas globais, podem gerar a partir dos coletivos locais, iniciativas de insurgência e resistência às forças que agridem particularidades e sentimentos de pertença a grupos minoritários, como a raça, a sexualidade, a religião, identidades humanas de cada um em si que se materializam e ganham força revolucionária quando reunidas em coletivos.

Campo Grande configura-se assim, historicamente, como um território de resistências, onde as mobilizações coletivas se apresentam, ora como agentes de mudança, ora como espaços de esperança. A nossa utopia espaço-temporal possível é de que surjam a partir da evolução da escala destas mobilizações locais e identitárias, através da união em rede e imperiosamente territorial e de forma presencial em ações afirmativas:

i. Coletivos mais bem estruturados e organizados;

ii. Movimentos sociais fortes e reconhecidos nacional e mundialmente, impactantes nas defesas de suas causas, como o MST (Movimento dos Trabalhadores Rurais sem Terra), o MNLP (Movimento Nacional de Lutas pela Moradia), a Central de Movimentos Populares (CMP), a Rede Brasil Sul de economia justa e solidária, o Projeto Brasil Cidades de luta pelo direito à cidade, entre outros.

A partir desta integração a lutas de maior escala e mais bem estruturadas e estabelecidas, é sim possível que os coletivos de Campo Grande construam conjuntamente a outras forças da sociedade civil organizada a utopia do movimento revolucionário global em rede, que possa alavancar a supressão do modelo capitalista por um novo modelo que retorne à comunidade humana o sentimento de pertença à comunidade universal, coabitante de uma casa comum, o espaço planetário.

\section{CONSIDERAÇÕES FINAIS}

A análise das mobilizações coletivas em curso na Região Administrativa de Campo Grande, Rio de Janeiro, permitem concluir que estes coletivos, desde que:

i. Consolidem uma consciência de classe, pautada no entendimento da exclusão de direitos e apropriação de bens comuns característica do modelo de acumulação capitalista, como raiz das demandas reivindicadas e geradora das mobilizações; 
ii. Escalonem suas iniciativas locais e identitárias para pautas estruturantes de ações planejadas e conduzidas a escalas regionais, nacionais e globais;

iii. Aproximem-se de partidos populares, organizações e entidades centralizadoras e integradoras de outros coletivos e movimentos sociais, participando das iniciativas em rede de indignação globais insurgentes, valendo-se além de criatividade e boa vontade, da participação efetiva nas novas formas de adesão e associação, para além do uso de ferramentas e Tecnologias da Informação e Comunicação (TICs);

Uma vez cumpridos estes requisitos de luta, estes grupos, carregam potencial e assim são convocados a participar da construção utópica da revolução anticapitalista e apresentação de um novo modelo de sociedade. E esta revolução, segundo Lefebvre (2008) é urgente frente às crises que o mundo atravessa, as quais têm por origem o estágio atual do capitalismo.

\footnotetext{
Esta revolução total e planetária, econômica, demográfica, psíquica, cultural, etc., é hoje, por excelência o impossível-possível (a possibilidade, a necessidade e a impossibilidade!). Nada mais próximo, mais urgente. Nada mais fugidio, mais longínquo. A ideia da revolução remete do mundial à conjuntura, do total à prática imediata, ou seja, a existência de uma enorme maioria, silenciosa ou não, de pessoas que aderem ao presente e chegam até a aceitar o milenarismo, porque ele remete para mais tarde a eventualidade de uma catástrofe. (LEFEBVRE, 2008, p.20)
}

Dois coletivos, dentre as dezenas de mobilizações coletivas atuantes na Região de Campo Grande, RJ, se destacam pela abrangência de suas pautas de luta, como a formação da FARD-ZO (Frente Ampla de Resistência Democrática da Zona Oeste) e pelo nível de relacionamento com partidos, movimentos sociais, coletivos, ONGs e lideranças nacionais e internacionais, e assim podem alcançar, com ajustes na comunicação e formas de atuação, visibilidade maior, nacional e até mundial, de suas práticas e resultados. São eles, o CEPMMA (Coletivo de Educação Popular Margarida Maria Alves) e o Coletivo Tudo Numa Coisa Só, como forças transformadoras do espaço em que atuam.

Uma potência destes coletivos reside na capacidade de organização e na agilidade em propor estratégias e propostas de ação, bem como a capacidade de levar a efeito as propostas que defendem. Estes coletivos, atualmente se configuram como como fontes de agentes e ativistas para os movimentos sociais tradicionais e de quadros novos para os partidos políticos, ONGs e órgãos governamentais. Sendo assim importantes agentes de construção e 
reconfiguração da sociedade nos territórios em que atuam. Um exemplo foi a eleição pelo PSOL, do Vereador William Siri, principal liderança do Coletivo Tudo Numa Coisa Só.

Reside em nossa reflexão proposta neste artigo a esperança de que no mundo de hoje, mergulhado no caos da pandemia, do desemprego, da recessão. Porém, ao mesmo tempo, capaz de experimentar em toda parte do globo iniciativas de solidariedade e cuidado com as pessoas mais frágeis e vulneráveis e com o meio ambiente, subsistem pessoas capazes de se organizar e pensar a partir de desejos únicos e identitários, objetivos coletivos e comuns.

A nossa utopia, a qual insistimos ser possível desde que a construamos, é de que estas iniciativas sejam mais ágeis e eficazes do que as perigosas e potentes ameaças que o convalescente modelo capitalista ainda pode nos propiciar, como as guerras, a fome, as pandemias, o desastre ambiental.

Construir a utopia é urgente começando por pequenos gestos revolucionários locais, os quais reconfigurados e escalonados, podem atingir o sonho do bem viver em uma sociedade, sócio e ambientalmente global, porém igualitária, justa e pacífica para todos os seres.

\section{REFERÊNCIAS}

ABREU. Maurício A. Evolução Urbana do Rio de Janeiro. $4^{\text {a }}$ ed. Rio de Janeiro, IPLANRio/Zahar. 1987.

CANO, Ignacio; DUARTE, Thais. "No sapatinho": a evolução das milícias no Rio de Janeiro (2008-2011). Rio de Janeiro, Fundação Heinrich Böll. 2012.

CARNEIRO, Henrique S. Apresentação - Rebeliões e ocupações de 2011. In Harvey, David et al. Ocupy; Movimentos de protesto que tomaram as ruas. São Paulo, Boitempo: Carta Maior, 2012.

CASTELLS, Manuel. A questão urbana. Tradução Arlete Caetano. Rio de Janeiro, Paz e Terra. 1983.

CASTELLS, Manuel. Redes de indignação e esperança: movimentos sociais na era da Internet. Rio de Janeiro, Zahar. 2017.

FRANCISCO. Carta encíclica "Laudato Si" - Louvado Sejas: Sobre o cuidado da casa comum. São Paulo, Paulus, Edições Loyola,2015.

FULGENCIO, Edivan de O. Mobilizações coletivas de Campo Grande, RJ, do direito à cidade à utopia anticapitalista global..Rio de Janeiro, 2020. 176f. Dissertação (Mestrado em Geografia) - Universidade do Estado do Rio de Janeiro (UERJ), 2020. 
HARVEY, David. 17 contradições e o fim do capitalismo. Tradução Rogério Bettoni. São Paulo, Boitempo. 2016.

HARVEY, David. A produção capitalista do espaço. São Paulo, Annablume. 2005.

HARVEY, David. Cidades rebeldes: do direito à cidade à revolução urbana. Tradução Jeferson Camargo. São Paulo: Martins Fontes, 2014.

\section{[texto removido]}

LEFEBVRE, Henri. Espaço e política. Tradução Margarida Maria de Andrade, Sérgio Martins. Belo Horizonte, Ed. UFMG, 2008.

LEOPOLDO, Eudes. LEVY, Charmain. A sociedade política como elemento central na relação entre movimentos sociais e governos: o caso do Partido dos Trabalhadores. In: ROMẪO, Wagner de Melo; MARTELLI, Carla Gandini Giandi (orgs). Participação política no Brasil. Ação coletiva e interfaces socioestatais. São Paulo, Cultura Acadêmica. 2014.

MARICATO, Ermínia. As ideias fora do lugar e o lugar fora das ideias - planejamento urbano no Brasil. In: ARANTES, O.; VAINER, C.; MARICATO, E. A Cidade do Pensamento Único: desmanchando consensos. Petrópolis: Vozes, 2000. pp. 121-192.

SANTOS, Milton. A Natureza do Espaço: Técnica e Tempo, Razão e Emoção. 4. ed. São Paulo, Universidade de São Paulo. 2006. 